\section{PENELITIAN PEMANFAATAN PARAFINIC OIL SEBAGAI BAHAN PLASTILIZER SECONDER DALAM PEMBUATAN KULIT IMITASI UNTUK ATASAN SEPATU}

Oleh : Hadi Musthofa, Sri Nadilah, Suprapto.

\section{ABSTRACT}

The aim of this research is to use Parafinic oil as Secondary Plaslizer in making PVC imitation leather for upper shoes and to know the optimal formulation. The reseach applied parafinic oil type $P 60$ and type $P 95$ and with variation 4 part, 5 part and 6 part. Data analysed using statistic method. Completly Randomized Design and Split plat Design. The result of this research indicated that all Kind of Parafinic Oil Could be used to secondary plastilizer in making imitation leather and the result of this phisical testing optimal parafinic oil type P60.4.

\section{INTISARI}

Penelitian ini bertujuan untuk memakai Parafinic oil sebagai bahan plastilizer seconder dalam pembuatan kulit imitasi untuk atasan sepatu dan untuk mengetahui formula yang optimal. Dalam penelitian ini dipergunakan Parafinic Oil tipe P 60 dan tipe P95 dengan variasi jumlah 4 bagian, 5 bagian dan 6 bagian. Analisa data dengan menggunakan Kan Completely Randomized Design dan Split plat Design. Hasil penelitian menunjukkan bahwa semua tipe parafinic oil dapat dipergunakan sebagai secondary plastiliser dalam pembuatan kulit imitasi dan hasil uji fisis parafinic oil tipe P60.4 yang optimal.

\section{PENDAHULUAN}

Kulit imitasi merupakan kulit tiruan yang dalam pembuatannya menyerupai bentuk kulit aslinya dan di Indonesia sudah cukup terkenal pada umumnya banyak dipakai dibidang interior, untuk jok mebel, jok kendaraan bermotor, pakaian khusus, tas, atasan sepatu dan lain sebagainya. Pemakaian dalam jumlah besar ini karena harganya terjangkau oleh konsumen yang memerlukannya. Selain itu juga mensubtitusi kebutuhan kulit aslinya yang sampai saat ini belum dapat tercukupi.

Keuntungan yang diperoleh dengan pemakaian kulit imitasi meliputi :

Dapat dibuat macam-macam rajah.

- Dapat dibuat macam-macam warna.

Mudah untuk dibersihkan

- Fleksibelitasnya tinggi.

- Memiliki nilai plastisitas yang luas.

- Mudah adaptasi dengan adanya perubahan model.

Majalah Barang Kulit, Karet dan Plastik
- Tahan terhadap sinar matahari.

- Dapat diproduksi dengan biaya murah.

Adapun Kelemahannya :

- Masing-masing lapisan penyusunnya tetap kelihatan terpisah dengan nyata, sedangkan pada kulit aslinya lapisan penyusun tidak terlihat dengan nyata pada bagian batasnya.

- Kekuatan sobek, tegangan putus, perpanjangan putus masih dibawah kulit aslinya.

- Porasitas kulit imitasi dibawah kulit aslinya.

- Penyerapan atau kelembapan masih jauh berbeda.

- Jika bahan ini langsung dikenakan pada kaki terasa kurang enak dan mudah terbentuk kerut

Pada pembuatan kulit imitasi, maka penambahan bahan pemlastis dapat mempengaruhi sifat kelunturan.

Bahan pemlastis yang digunakan mempunyai sifat :

- Titik didih tinggi.

- Tidak mudah menguap.

- Mempunyai berat molokul minimal 350.

- Pada suhu kamar dapat melarutkan polimer tetapi dalam waktu yang lama, dapat dipercepat bila suhu dinaikan $(3,4)$.

Karakteristik plastiliser diukur dengan tidak munculnya plastilizer kepermukaan, efisiensinya ditentukan oleh banyaknya plastilizer untuk memberi kan sifat keras dan fleksibel, stabilitas panas pada plastilizer dimaksudkan sebagai pertahanan terhadap degradasi pada suhu yang tinggi dan penguapannya.

Berdasarkan susunan kimianya plastilizer digolongkan menjadi :

- Fospat.

- Flalat

- Ester olifatik.

Untuk dapat memperoleh sifat yang diinginkan perlu dipakai plastilizer dalam jumlah yang cukup besar. Derivat pletalat yang sering digunakan dalam kompon PVC adalah Dioktil pletalat,karena disamping harganya lebih murah juga mempunyai kemampuan kerja yang lebih baik. Berdasarkan sifat kompodilitas dan resin plastiliser dibedakan menjadi dua macam yaitu : plastilizer primer dan plastilizer sekunder ( 2,4$)$, sebagai plastilizer primer yang sering dipergunakan oleh industri PVC berupa Dioktil pletalat, sedangkan untuk plastilizer sekunder yang digunakan dalam bentuk senyawa hidrokarbon dan berfungsi sebagai subtitusi dengan tujuan untuk memperendah proses berikutnya, dapat memperbaiki terhadap ketahanan resistivitas listrik dan sifat fleksibilitas serta menekan harga. (4).

Vol. XII No. 24 Th. $1996 / 1997$ 
Pada proses pembuatan kompon PVC maka pemakaian plastilizer sekunder dalam pencampuran harus dapat terdispersi secara homogen dan dapat bergabung dengan plastilizer primernya, sehingga selama dalam penyimpanan ataupun pada uji tekanan diantara celah-celah rol, maka plastilizer sekunder tidak terpisah dari kompon PVC.(4).

Pendapat dari Bill dan Adam bahwa pada pembuatan kompon PVC dengan menggunakan bahan plastilizer primer dalam bentuk dioktil pletalat sebesar 50 60 bagian, sedangkan pemakaian bahan plastilizer sekunder sebagai bahan pensubtitusi kedalam kompon sebesar 5 - 10 bagian.

Parafinik oil yang merupakan salah satu hasil samping dari lube ekstrak penggilingan minyak di Cilacap Pertamina merupakan jenis aromatik dan menurut perkiraan dapat dipakai sebagai bahan plastilizer sekunder dalam proses pembuatan kulit imitasi dengan bahan baku PVC. Adapun parafinic yang dihasilkan tersebut diberi kode P60 dan P95. Parafinic yang semula mempunyai nilai ekonomisnya yang rendah dan dengan adanya variasi dalam penggunaan sebagai plastilizer sekunder pada pembuatan macam produk plastik maka nilai ekonomisnya dapat ditingkatkan.

\section{MATERI DAN METODE PENELITIAN}

Dalam melaksanakan penelitian ini diperlukan materi dalambentuk bahan dan peralatan sebagai berikut :

Bahan :

- Resim PVC emulsi.

- Epoxy oil.

- Plastilizer DOP.

- Stabilizer panas BaCd karbon black.

- CaCO3 aktif.

- Asam stearat.

Parafinic oil P 60 dan P 95 tipe 2 dan 3.

- Pigmen hitam.

- Kain flanel.

- Metil etil keton.

- Kertas embos.

Alat yang digunakan :

- Hand anixer.

- Martil dan stanfer.

- Rol stainless stell.

- Oven.
- Neraca.

- Stop watch.

- Alat uji sifat fisis (Tensile strength, tering strength, Abrassion tester, mikrometer, fleksometer).

\section{METODE PENELITIAN}

Pada penelitian pemanfaatan parafinic oil sebagai plastilizer sekunder dalam pembuatan kulit imitasi dengan mempergunakan formula sebagai berikut :

Tabel 1. Formula kompon PVC untuk kulit imitasi.

\begin{tabular}{|l|c|c|c|}
\hline \multirow{2}{*}{ Nama Bahan } & \multicolumn{3}{|c|}{ Jumlah ( Bagian ) } \\
\cline { 2 - 4 } & Top Coat & Midle Coat & Base Coat \\
\hline Resin PVC Emulsi & 100 & 100 & 100 \\
DOP & 70 & 70 & 70 \\
Parafinic oil & $4,5,6$ & $4,5,6$ & $4,5,6$ \\
Epoxy oil & 3 & 3 & 3 \\
Ba Cd Zn komplek & 5 & 5 & 5 \\
CaCO3 & 10 & 10 & 10 \\
Asam Stearat & 1 & - & - \\
Pigmen hitam & 1 & - & - \\
\hline
\end{tabular}

Rincian banyaknya kompon yang dibuat untuk keperluan uji fisis dan organoleptis sebagai berikut

- Parafinic oil 2 jenis, 2 tipe 4 macam jumlah 12 macam, masing masing dibuat 3 variabel $=3 \times 4=12$

- Masing-masing dibuat sebanyak 500 gram

- Lembaran kulit imitasi dibuat dengan ukuran Panjang x lebar $=25 \times 45 \mathrm{Cm}$

- Tiap variabel parafinic oil dibuat masing-masing 5 lembar untuk keperiuan uji fisis dan organoleptis

Kondisi operasi pada pembuatan kulit imitasi dengan komposisi kompon diatas dilaksanakan dengan cara sebagai berikut : 
Tabel 2. Kondisi proses pembuatan kulit imitasi.

\begin{tabular}{|l|c|c|c|}
\hline Lapisan & Suhu $\left({ }^{\circ} \mathrm{C}\right)$ & Waktu (menit) & Tebal (mm) \\
\hline Atas & 140 & 5 & 0,3 \\
Tengah & 150 & 6 & 0,2 \\
Dasar & 170 & 10 & 0,1 \\
\hline
\end{tabular}

Pada penelitian penggunaan parafinic oil sebagai plastilizer sekunder dalam pembuatan kulit imitasi dengan menggunakan matrik sebagai berikut :

Tabel 3. Matrik Pemakaian Parafinic Oil

\begin{tabular}{|l|c|c|c|c|c|}
\hline \multirow{2}{*}{ Jenis } & \multicolumn{5}{|c|}{ tipe 2 } \\
\cline { 2 - 6 } & 4 Bagian & 5 Bagian & 6 Bagian & 5 Bagian & 6 Bagian \\
\hline P 60 & P 602.4 & P 602.5 & P 603.4 & P60 3.5 & P 603.6 \\
P 95 & P 952.4 & P 95 2.5 & P 953.4 & P 95 3.5 & P 95 3.6 \\
\hline
\end{tabular}

Proses pembuatan lembaran dilaksanakan dengan urutan sebagai berikut :

- Bahan ditimbang sesuai dengan jumlah yang diperlukan.

Bahan yang berbentuk powder ditambah bahan cair sedikit demi sedikit demi sedikit, diblending sampai homogen. Pencampuran pada top coat, bahan pewarna diblending terlebih dahulu dengan sedikit penambahan Dioktil pletalat, selanjutnya ditambahkan bahan berbentuk powder lain serta bahan cair yang lain dan penambahan ini dilaksanakan secara bergantian sedikit-sedikit sampai habis.

- Bahan selanjutnya dimasukkan dalam wadah dan di mixing sampai homogen .

- Menyiapkan kertas embos dan kain penguat yang mempunyai ukuran 45 x 35 $\mathrm{Cm}$.

- Proses pelapisan menjadi lembaran kulit imitasi.

Mula-mula kertas embos diletakkan diatas kaca.

- Kompon top coat dioleskan dengan memakai rol yang ketebalannya 0,3 mm diatas kertas embos secara merata, masukkan dalam oven dan suhu diatur konstan pada $150^{\circ} \mathrm{C}$ selama 6 menit kemudian didinginkan .

Kompon middle dioleskan diatas kompon top coat dengan rol yang mempunyai ketebalan 0,5 keringkan dalam oven pada suhu $150^{\circ} \mathrm{C}$ selama 6 menit selanjutnya dinginkan.

Kompon base coat dioleskan diatas lapisan midle dengan rol ketebalannya 0,6 $\mathrm{mm}$.
- Letakkan kain penguat diatas lapisan base yang masih basah, keringkan dalam oven dan suhu dipertahankan kostan pada $170^{\circ} \mathrm{C}$ selama 10 menit, selanjutnya dinginkan.

- Pisahkan kertas embos dengan kulit imitasi secara hati-hati.

\section{Tahap Pengujian.}

Pengujian sifat fisika lembaran kulit imitasi PVC meliputi :

- Kuat tarik.

- Perpanjangan putus.

- Ketahanan sobek.

- Ketahanan rekat antara lapisan plastik dan penguat.

- Kekuatan jahit.

Ketahanan bengkuk.

Ketahanan kikis.

Ketahanan warna pengaruh WOM.

Uji Organoleptis.

Analisa hasil uji dengan menggunakan statistik Completely Randomi-zed design dan dilanjutkan Split Plat Design, untuk hasil terbaik dibandingkan dengan formula standar dengan metode CRD sehingga dapat diketahui dapat diketahui pengaruh parafinic oil terhadap sifat fisika kulit imitasi.

\section{Hasil Penelitian Dan Pembahasan}

Kulit imitasi yang sudah dibuat dalam bentuk lembaran selanjutnya dilakukan pengujian baik sifat fisika maupun sifat organoleptis. Adapun hasil uji kulit imitasi yang dalam pembuatannya dengan mempergunakan formula secara standar secara terinci dapat dilihat pada tabel 4 terlampir. Berdasarkan data hasil uji sebagai mana yang terdapat dalam tabel tersebut ternyata kulit imitasi yang berasal dari formula standar baik sifat fisika maupun organoleptisnya sudah memenuhi standar Industri Indonesia N0. 1645-85, standar mutu kulit imitasi untuk atasan sepatu.

Pada kulit imitasi yang dalam pembuatannya menggunakan plastilizer sekunder berupa parafinic oil jenis P 60 dan jenis P95 hasil uji secara terinci dapat dilihat pada tabel 5 terlampir. Dari data tersebut dapat diketahui bahwa parafinic oil baik $\mathrm{P} 60$ maupun $\mathrm{P} 95$ dalam pemakaian dari 4 bagian sampai 6 bagian kedalam kompon PVC, dapat menghasilkan produk kulit imitasi yang memenuhi persyaratan mutu SII No. 1645-85 " syarat mutu kulit imitasi untuk atasan sepatu " bahkan pemakaiannya kedua bahan tersebut dapat menaikkan sifat fisikanya bila dibandingkan dengan kulit imitasi hasil formulasi standar. Hal ini terlihat pada

Vol. XII No. 24 Th. $1996 / 1997$ 
penggunaan bahan P 60 sebanyak 4 bagian dapat memperbaiki kuat jahit arah melintang, ketahanan kikis, kuat rekat arah melintang dan membujur, kuat sobek arah membujur dan kuat tarik arah membujur, sedangkan pemakaian $\mathrm{P} 60$ sebanyak 6 bagian sifat fisika yang diperbaiki berupa kuat tarik arah melintang, kemuluran arah membujur dan arah melintang. Untuk pemakaian P 95 sebanyak 6 bagian memperbaiki sifat kuat sobek arah melintang dan kuat jahit arah membujur.

Penentuan jumlah penggunaan parafinic oil yang optimal dengan cara diadakan analisa statistik metode Completely Random Design, dari 11 jenis uji yaitu kekuatan tarik melintang membujur, mulur arah melintang dan membujur, ketahanan sobek melintang dan membujur, ketahanan rekat antara lapisan plastik dan penguat arah melintang dan membujur, ketahanan kikis dan kekuatan jahit arah melintang dan membujur dari 12 jenis parafinic oil diperoleh 4 bagian parafinic oil $46,97 \%$ optimal, 5 bagian parafinic oil $28,03 \%$ optimal, 6 bagian parafinic oil $25 \%$ optimal, sehingga dengan demikian dapat dikatakan bahwa penggunaan parafinic oil sebagai secondary plastilizer dalam pembuatan kulit imitasi yang terbaik adalah 4 bagian .

Berdasarkan analisa statistik dengan metode "Split Plat design ", hasil perhitungan LSD interaksi sebagai berikut:

Subtreat ( tipe parafinic oil ) dalam 1 level maintreat ( jenis parafinic oil ) ada kecenderungan :

$$
\text { - } \mathrm{P} 602=\mathrm{P} 603 \text {. }
$$$$
\text { - } \mathrm{P} 952=\mathrm{P} 952 \text {. }
$$

Maintreat (jenis parafinic oil) level subtreat (tipe parafinic oil) ada kecenderungan :

- $\mathrm{P} 602=\mathrm{P} 952$.

- $\mathrm{P} 603=\mathrm{P} 953$.

- Hasil optimal P 604.

Dari hasil perhitungan statistik metode CRD untuk membandingkan hasil optimal yang paling baik yaitu P 603.4 dengan standar, menggunakan tolok ukur SII. 1645 - 85 ternyata bahwa P 602.4 kulitasnya lebih baik dibanding dengan standar, hal ini berarti bahwa pemakaian parafinic oil sebagai plastilizer sekunder dalam pembuatan kulit imitasi PVC mempunyai pengaruh dalam peningkatan mutu. Ada kecenderungan P 602.4 dan standar saling berbeda nyata.

\section{KESIMPULAN}

1. Parafinic oil produksi PERTAMINA dapat berfungsi sebagai plastilizer sekunder dalam pembuatan kulit imitasi PVC dan dan sesuai dengan SII $1645-85$.
2. Batas penggunaan optimal parafinic oil adalah 4 bagian/100 bagian resin PVC.

3. Parafinic tipe $P 60$ dan tipe $P 95$ ada kecenderungan tidak berbeda nyata sehingga bisa mengganti satu sama lain, hasil terbaik pada pemakaian P 603.4.

4. Dalam bentuk barang jadi (lembaran kulit imitasi) pemakaian parafinic oil 60 dan 95 tipe 2 dan 3 tidak mempengaruhi kenampakan dari kulit imitasi, hal ini mempengaruhi performance yang cukup baik terutama untuk warna hitam dan warna-warna gelap.

\section{DAFTAR PUSTAKA.}

1. Departemen Perindustrian "SII. 1645 - 85 Standar Kulit Imitasi Untuk Atasan Sepatu "Jakarta 1986.

2. Gupta, R.K. "Plastic Coating And Lamination Technology And Plastik Dirrectory "Small Business Publication Roop Nagar, Delhi- 110007.

3. Soepranoto, Drs dkk. "Kompon PVC lembaran kulit imitasi dengan jumlah variasi blowing agent dan suhu pada proses pembuatan kulit imitasi." BBKKP Yogyakarta.

4. Sugandi M. dan Kun Harimurti "Lembaran plastik dan penggunaannya" P2MP Jakarta, 1982. 